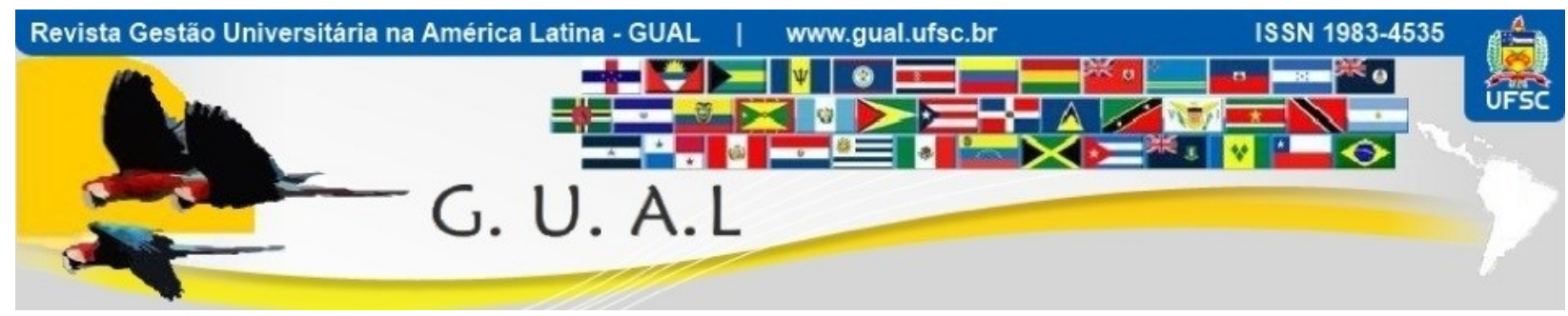

DOI: http://dx.doi.org/10.5007/1983-4535.2015v8n1p132

\title{
A DEFINIÇÃO DO PERFIL DE VULNERABILIDADE PARA ACESSO À POLÍTICA DE PERMANÊNCIA NO ENSINO SUPERIOR
}

\section{DEFINITION OF A PROFILE OF VULNERABILITY TO ACCESS POLICY OF PERMANENCE IN HIGHER EDUCATION}

\author{
Lilian Tedy Pereira, Mestre \\ Universidade Federal de Santa Catarina - UFSC \\ lilian.tedy@ufsc.br \\ Mário de Souza Almeida, Doutor \\ Universidade Federal de Santa Catarina - UFSC \\ mario.almeida@ufsc.br
}

Recebido em 06/janeiro/2014

Aprovado em 27/novembro/2014

Sistema de Avaliação: Double Blind Review

Esta obra está sob uma Licença Creative Commons Atribuição-Uso. 


\title{
RESUMO
}

Este estudo busca analisar o sistema de estudo socioeconômico realizado nas Universidades. Os fundamentos que balizaram o estudo foram: Conhecimentos dos Profissionais da Equipe de Serviço Social, a Delimitação da concepção de Vulnerabilidade, Gestão das Políticas de Permanência e o Instrumental Técnico Operativo utilizado no Estudo Socioeconômico. No desenvolvimento da pesquisa, utilizou-se uma abordagem qualitativa de natureza aplicada com caráter descritivo do estudo de multicaso. Para coleta de dados foi utilizada a pesquisa documental, bibliográfica e o questionário encaminhado via e-mail aos gestores das equipes de Assistentes Sociais de cinco universidades. Nas informações obtidas foi possível identificar as formas utilizadas para o estudo socioeconômico nas universidades. Embora as formas adotadas de construção das metodologias apresentem a preocupação com as bases teóricas, que são principalmente desenvolvidas a partir dos conhecimentos dos Assistentes Sociais, não fica clara a definição de uma teoria específica para estudo socioeconômico.

Palavras-chave: Estudo socioeconômico. Gestão da Assistência. Gestão da Permanência.

\begin{abstract}
This study assesses the system of socioeconomic study in universities. The fundamentals that guided the study were: knowledge for Professional Social Work Team, the concept of vulnerability, Permanence Management Policies and Technical Operating Instrumental used in the Socioeconomic Study. In developing the survey, it has a qualitative approach and applied nature, with descriptive multicase study. The data collection was documentary, bibliographical and was used questionnaire sent via e-mail to managers of teams of social workers from five universities. Through the information obtained, it was possible to identify the forms used for the socioeconomic study in universities. Although the adopted forms for construction of the methodologies present concern with the theoretical bases, which are mainly developed from the knowledge of Social Workers, there is not a clear definition of a theory to specific socioeconomic study.
\end{abstract}

Keywords: Socioeconomic Study. Assistance Management. Permanence Management. 


\section{A DEFINIÇÃO DO PERFIL DE VULNERABILIDADE PARA ACESSO À POLÍTICA DE PERMANÊNCIA

\section{INTRODUÇÃO}

O contexto da gestão da assistência estudantil do ensino superior, exige a flexibilização dos procedimentos, em um ambiente de mudanças contínuas, e que desde a aprovação das cotas sociais, como também da adoção das ações afirmativas para ingresso nas universidades federais, vem em crescente demanda.

O desafio proposto para a gestão universitária é entender essa realidade como um sistema social complexo, onde as novas tecnologias podem superar o modelo de organização formal, burocrático e demorado, possibilitando aos profissionais que realizam esse tipo de estudo, um conhecimento compartilhado, que contribua para a metodologia e que também supere as distorções subjetivas.

No serviço público, a inovação é essencial para manter o Estado atualizado, com um aparelho e práticas adequados para atender aos anseios da sua sociedade, que em última análise caracteriza-se por sua razão de existir. "A inovação se origina da necessidade de sobrepor-se ou de adaptar-se aos obstáculos ambientais, ao crescimento e ao desenvolvimento dos mesmos e da necessidade de lutar pela sobrevivência das organizações" (MOTTA, 1979, p.176).

Damanpour, Szabat e Evan (1989 apud MENNA; SAUER, 1998) consideram que as inovações podem ser vistas sob dois aspectos: de natureza técnica ou de natureza administrativa. As inovações técnicas são, segundo os autores, aquelas que ocorrem no componente operacional e afetam o sistema técnico de uma organização, sendo que o sistema técnico consiste dos equipamentos e métodos de operação utilizados para transformar matériaprima ou informações em produtos ou serviços. As inovações administrativas, de acordo com os autores, são aquelas que ocorrem no componente administrativo e afetam o sistema social de uma organização.

Nessa perspectiva, considera-se que avaliar e propor novas formas para o sistema de estudo socioeconômico, envolve tanto os aspectos organizacionais como o instrumental técnico operativo dos profissionais da equipe, uma vez que pode gerar mudanças sociais no acesso aos estudantes.

A proposição da inovação de aperfeiçoar os recursos disponíveis, por meio de formas inovadoras de gestão e organização, promove o atendimento qualificado e a inovação como ferramenta para melhorar a gestão dos programas desenvolvidos e, por fim, garantir sua existência. 


\section{A DEFINIÇÃO DO PERFIL DE VULNERABILIDADE PARA ACESSO À POLÍTICA DE PERMANÊNCIA NO ENSINO SUPERIOR \\ DOI: http://dx.doi.org/10.5007/1983-4535.2015v8n1p132}

Para Miranda (2005), a administração pública, como é o caso da UFSC, continuamente procura modificar sua forma de gestão. Em seus sistemas de informação tem se deparado com os desafios propostos pelas demandas da população atendida, da informação e do conhecimento na utilização de novas tecnologias e metodologias. Assim, verifica-se que a gestão administrativa busca a adequação dos procedimentos das instituições públicas às novas formas de comunicar e de interagir. Esse caminho focaliza a desburocratização, o que possibilita o acesso à documentação por meio de tecnologias de informação.

Nesse sentido é importante refletir sobre formas de gestão construídas mediante um processo de aprendizagem, que precisa responder a uma necessidade institucional, enquanto instrumento da inovação, avaliando os procedimentos metodológicos utilizados pelos Assistentes Sociais.

Cruz Junior (1988), ao considerar as bases conceituais para uma nova ciência das Organizações, coloca:
A hora é chegada, portanto, para redescoberta das funções sobre as quais haveremos de assentar as bases conceituais de uma forma mais harmoniosa de vida humana em sociedade. É exatamente dentro desse contexto que um paradigma emergente de organização e administração de entidades públicas, baseado nos postulados da teoria da delimitação de sistemas, poderá atender de forma adequada, a esta necessidade de ordenação mais harmoniosa da vida humana associada, no âmbito generalizado da ciência social, e redefinição da própria noção de administração pública, no domínio específico da ciência organizacional (CRUZ JUNIOR, 1988, p. 20).

É importante refletir sobre a definição da metodologia, que estabelece os critérios de inclusão na política de permanência, pois exige a percepção das constantes mudanças da realidade social, que remete os estudantes a situação de risco de evasão ou ainda, às dificuldades de aproveitamento do ensino. O gestor deve avaliar as medidas que possibilitam o acesso à superação das situações de vulnerabilidade social, e os instrumentos inovadores que auxiliam na intervenção dos profissionais que atuam nessa totalidade.

Nessa perspectiva, pretende-se com este estudo "analisar o sistema de estudo socioeconômico realizado em universidades federais, para classificação e fixação dos estudantes do ensino superior a serem atendidos pela política de permanência”. 


\section{A DEFINIÇÃO DO PERFIL DE VULNERABILIDADE PARA ACESSO À POLÍTICA DE PERMANÊNCIA

\section{CONHECIMENTOS DOS PROFISSIONAIS DA EQUIPE DE SERVIÇO SOCIAL}

As demandas impostas para atendimento nas políticas de permanência têm levado à necessidade de definição do perfil de vulnerabilidade realizado por meio do estudo socioeconômico, que classifica os estudantes a serem atendidos.

Percebe-se a relevância do compartilhamento dos conhecimentos de maneira que tal estudo possibilite um conhecimento explícito a ser incorporado, aprimorando e apurando a análise dos profissionais que realizam o estudo.

Segundo Santos (2013), quanto aos aspectos que envolvem os mitos e dilemas da profissão de Assistente Social, situa-se o ensino de habilidades necessárias ao manuseio dos instrumentos e técnicas da intervenção, e considera-se que o problema está na qualidade do manuseio e não no instrumento propriamente dito. Para essa autora, a formação competente é aquela que conhece o mercado de trabalho, mas que não se limita por ele, e que incorpora o conhecimento das exigências postas, antecipando demandas e reconhecendo os instrumentos necessários à intervenção.

De acordo com o art. $4^{\mathrm{o}}$ da Lei n. 8.662/93, é de competência do profissional de Serviço Social "realizar estudos socioeconômicos com usuários, para fins de benefícios e serviços sociais junto a órgãos da administração pública direta e indireta, empresas privadas e outras entidades". Contudo, é atribuição privativa "realizar vistorias, perícias, técnicas, laudos periciais, informações e pareceres sobre a matéria do Serviço Social” (BRASIL, 1993).

Os estudos socioeconômicos podem ser definidos como o processo de conhecimento, análise e interpretação de uma determinada situação social. A sistemática metodológica para o estudo deve ser construída a partir de instrumentais técnico-operativos do Serviço Social acompanhados de entrevistas e acolhimento aos usuários, seguidos de parecer social.

O estudo socioeconômico também deve resguardar as condições éticas e técnicas do exercício profissional do assistente social, conforme a Resolução CFESS 493/2006, Art. $4^{\circ}$, onde determina que "o material técnico utilizado e produzido no atendimento é de caráter reservado, sendo seu uso e acesso restrito aos assistentes sociais" (CFESS, 2006).

Ao utilizar uma metodologia, segundo Santos (2013), esses aspectos técnico operativos e éticos políticos, devem ser garantidos de maneira a preservar o estudo socioeconômico, que é parte intrínseca das ações desenvolvidas pelos assistentes sociais, e pressupõe conhecimentos específicos adquiridos ao longo do processo de formação, tais como a compreensão das condições sociais em que vivem os estudantes, mediante a escuta 
qualificada de suas demandas, o acolhimento à Universidade, o esclarecimento de direitos sociais e de seus deveres institucionais.

\subsection{DELIMITAÇÃO DE VULNERABILIDADE}

Os estudos sobre vulnerabilidade social passaram a receber, nos últimos vinte anos, maior discussão como instrumentos de investigação da realidade atual do mundo do trabalho. Neste contexto, diversos autores, entre eles Castel (1997b), apontaram para os limites do conceito de exclusão social e buscaram avançar na discussão acerca do significado do conceito de vulnerabilidade social. A partir das críticas aos limites do conceito de exclusão social, alguns estudos passaram a apontar a existência de uma zona de vulnerabilidade, formada por setores pobres que buscam alternativas para estar incluídos, ou por setores médios empobrecidos que têm perdido canais de inclusão.

Nesse sentido, para Castel (1997a), a vulnerabilidade social é uma zona intermediária instável que conjuga a precariedade do trabalho e a fragilidade dos suportes de proximidade. Diante de uma crise econômica, o aumento do desemprego e a generalização do subemprego, a zona de vulnerabilidade aumenta e avança sobre a zona de integração e elimina a desfiliação.

A preocupação parece estar na identificação de zonas de vulnerabilidades, que envolvem desde os setores que buscam a melhoria do posicionamento social, até os setores médios que lutam para manter seu padrão de inserção e bem estar, ameaçados pela tendência a precarização do mercado de trabalho, tudo isso em confronto com a estrutura de oportunidades existentes em cada país em um dado momento histórico (CASTEL, 1997a).

Nos trabalhos de Katzman (2005) o conceito de vulnerabilidade social não é o mesmo que pobreza, mas a inclui. Ser pobre, segundo esse autor, é quando não se satisfazem as necessidades básicas, incluindo também aquelas pessoas que se encontram abaixo da linha de pobreza. $\mathrm{O}$ autor define vulnerabilidade:

Vulnerabilidade não é exatamente o mesmo que pobreza mas a inclui. Esta última está relacionada a uma situação de carência efetiva e certamente a vulnerabilidade transcende esta condição projetando no futuro a possibilidade de sofrimento a partir de certas debilidades, que se constatam no presente (KATZMAN, 2005, p. 04).

O autor amplia seu conceito, dizendo que: 
Em seu sentido amplo a categoria vulnerabilidade reflete as condições dos vulneráveis, que se assemelha a condição de pobreza, uma carência efetiva que implica na impossibilidade atual de sustentamento e desenvolvimento, em uma debilidade futura a partir desta incapacidade nas quais os vulneráveis para quem as condições de vida não estavam materializadas, aparecem como uma situação de grande probabilidade em um futuro certo, a partir das condições de fragilidade que os afeta (KAZTMAN, 2005, p. 04).

Este conceito permite concluir que a vulnerabilidade social está relacionada à menor capacidade de enfrentar situações de risco, de controlar as forças que afetam as possibilidades de aproveitar as oportunidades de boa inserção ocupacional propiciadas pelo Estado, mercado ou sociedade.

O estudo realizado pela UNESCO Organização das Nações Unidas para a Educação, a Ciência e Cultura e pelo BID Banco Interamericano de Desenvolvimento, trabalha a definição de Vignoli e Filgueira (2001 apud ABRAMOVAY et al., 2002, p.13) de vulnerabilidade social enquanto falta de ativos materiais e imateriais a que determinado indivíduo ou grupo está exposto a sofrer futuramente alterações bruscas e significativas em seus níveis de vida, sendo:

Vulnerabilidade social como o resultado negativo da relação entre a
disponibilidade dos recursos materiais ou simbólicos dos atores, sejam eles
indivíduos ou grupos, e o acesso à estrutura de oportunidades sociais
econômicas culturais que provêm do Estado, do mercado e da sociedade.
Esse resultado se traduz em debilidades ou desvantagens para o desempenho
e mobilidade social dos atores (ABRAMOVAY et al , 2002. 192 p.).

A vulnerabilidade social pode se manifestar em dois planos: estrutural e subjetivo. No plano estrutural, pode ser dada por uma mobilidade descendente e, no plano subjetivo, pelo desenvolvimento de sentimentos de incerteza, insegurança, de não pertencimento a determinado grupo e de fragilidade. Os jovens são fonte de potencialidade, com uma condição óbvia relacionada à idade, à habilidade do jovem, mas a vulnerabilidade social retira essa potencialidade inerente e remete à incerteza. Os mesmos autores afirmam que:

O conceito de vulnerabilidade ao tratar da insegurança, incerteza e exposição a riscos provocados por eventos socioeconômicos ou ao não acesso a insumos estratégicos apresenta uma visão integral sobre as condições de vida dos pobres, ao mesmo tempo em que considera a disponibilidade de recursos e estratégias para que estes indivíduos enfrentem as dificuldades que lhes afetam (VIGNOLI; FILGUEIRA, 2001 apud AMBRAMOVAY et al, 2002, p.34-35). 
Segundo Dieterlen (2001), vulnerabilidade é a falta de atendimento às necessidades básicas, que são negadas pelos detentores de poder:

E uma forma de vulnerabilidade consiste em ter necessidades básicas, visto que as pessoas que carecem dos meios de subsistência dependem do exercício do poder daqueles que podem lhes proporcionar e negar os meios de vida. As necessidades básicas refletem uma falta de poder e, portanto, uma situação de vulnerabilidade (DIETERLEN, 2001, p.19).

Esta autora trabalha com a ideia de que as populações atingem um grau de vulnerabilidade que não podem ter a capacidade de "escolher ou rejeitar o que os faz sofrer" (DIETERLEN, 2001, p.19). Eliminar as situações de vulnerabilidade tanto compete aos gestores públicos quanto aos cidadãos.

Observa-se, portanto, que essas situações de vulnerabilidade no mundo do trabalho são constitutivas das sociedades capitalistas, que são movidas pela competição e guiadas por uma lógica que reproduz a desigualdade social.

Considerando as concepções trazidas, pode-se afirmar que a vulnerabilidade social está associada também à ideia de risco, frente ao desemprego, à precariedade do trabalho, à pobreza e à falta de proteção social. Vulnerabilidade social é formada por pessoas e lugares, que estão expostos à exclusão social, são famílias, indivíduos sozinhos, que apresentam sinais de risco social, ou seja, tornam-se excluídos, dos bens e recursos oferecidos pela sociedade.

Dentre esses enfoques sobre vulnerabilidade social, verifica-se um consenso sobre uma questão fundamental: a capacidade de observar as situações intermediárias de risco localizadas entre situações extremas de inclusão e exclusão, dinamizando o estudo das desigualdades.

Considerando as contribuições apresentadas, verifica-se que as situações de vulnerabilidade social estão associadas à capacidade de enfrentar determinadas situações de risco, referindo-se, portanto, à maior ou menor capacidade de um indivíduo, família ou grupos sociais de controlar as forças que afetam seu bem-estar, ou seja, as condições que constituem os recursos requeridos para o aproveitamento das oportunidades propiciadas pelo Estado, mercado ou sociedade.

\subsection{A GESTÃO DAS POLÍTICAS DE PERMANÊNCIA}

Segundo Rocha (1997), até a década de 1990, pode-se verificar a inexistência de recursos em uma perspectiva nacional voltados para a assistência estudantil na educação 


\section{A DEFINIÇÃO DO PERFIL DE VULNERABILIDADE PARA ACESSO À POLÍTICA DE PERMANÊNCIA \\ NO ENSINO SUPERIOR \\ DOI: http://dx.doi.org/10.5007/1983-4535.2015v8n1p132}

superior. Nesse período, apesar de ter início um processo de discussão sobre o assunto, a assistência estudantil ainda tomava uma forma fragmentada e se restringia a instituições isoladas.

As políticas de assistência estudantil da primeira fase, isto é, até a década de 1990, tiveram um caráter pontual, marcado pela escassez de recursos. As políticas de certa forma seguiram a reestruturação que a sociedade vinha passando e novo formato que propunha a educação superior no Brasil, bem como a sua consolidação enquanto grau de ensino. É possível perceber que as políticas de assistência estudantil nesse período seguiram as tendências e os interesses políticos do momento.

Para Castro (2010), a segunda fase das políticas voltadas para a assistência estudantil é marcada por um momento em que a sociedade entra em processo de democratização, e foi apenas no início da década de 2000, que tais ações passaram a ganhar uma perspectiva de uma política governamental.

Entre as políticas adotadas pelo Governo Federal com reflexos na assistência e permanência estudantil, bem como no perfil dos estudantes a serem atendidos, destaca-se o Programa de Expansão e Reestruturação das Universidades Federais/ REUNI. Entre suas consequências, esse plano resultou na adoção de cotas sociais nas universidades, bem como na gestão dos setores que desenvolvem as políticas e os programas de Assistência Estudantil (BRASIL, 2007).

O projeto REUNI, ao prever as mudanças nas Instituições Federais de Ensino Superior, e ao possibilitar instrumentos para o enfrentamento desses desafios, que se expressam na defesa da expansão de vagas para o ensino superior, no incentivo a novas tecnologias didático metodológicas, no apoio a medidas para valorizar currículos modernizados e qualificados, no incentivo a formações disciplinares e curriculares diversificadas, na vinculação da graduação à pós-graduação e, nos recursos financeiros, supera a visão de uma mera expansão quantitativa das matrículas.

No Decreto 6.096/2007, é anunciado o objetivo do Programa de criar condições para ampliação do acesso e permanência na educação superior, e as metas que envolvem a gestão da estrutura física e dos recursos humanos existentes nas universidades federais. Nestes termos, a finalidade de aperfeiçoar a capacidade instalada dos cursos de graduação, visando a sua ampliação no acesso e na permanência, estimulo à interdisciplinaridade, fica evidenciada na meta de reestruturação das universidades (BRASIL, 2007). 


\section{A DEFINIÇÃO DO PERFIL DE VULNERABILIDADE PARA ACESSO À POLÍTICA DE PERMANÊNCIA \\ NO ENSINO SUPERIOR \\ DOI: http://dx.doi.org/10.5007/1983-4535.2015v8n1p132}

Atualmente a gestão da assistência estudantil nas universidades federais está definida pelo Decreto $\mathrm{n}^{\mathrm{o}}$ 7234, de 19 de julho de 2010, que cria o Plano Nacional de Assistência Estudantil/PNAES, com a finalidade de auxiliar os estudantes matriculados em cursos de graduação presencial de instituições federais de ensino superior. Esse plano tem entre seus objetivos, "subsidiar a permanência de alunos de baixa renda nos cursos de graduação, com intuito de diminuir a desigualdade social e possibilitar a democratização na educação superior" (BRASIL, 2010). Considera-se fundamental apresentar essas informações, pois esse plano estabelece critérios e define alguns aspectos da realização do estudo socioeconômico.

O contexto da Gestão da Assistência Estudantil do Ensino Superior, conforme pode ser observado, é dinâmico e as suas mudanças contínuas geram reflexos; como a alteração do perfil socioeconômico e a crescente demanda dos estudantes, o que requer a constante revisão dos procedimentos utilizados nas ações sócio assistenciais.

As políticas de acesso e permanência do Ministério da Educação apontam para definição de vulnerabilidade, trazendo a renda per capita como fator excludente na sua concessão. A vulnerabilidade social nessa visão é medida através da linha de pobreza, que é definida por meio dos hábitos de consumo das pessoas, estabelecendo o valor equivalente a um salário mínimo e meio.

A orientação de considerar a renda per capita como definidora do perfil de vulnerabilidade pode ser verificada já no sistema de cotas sociais para ingresso nas universidades por meio da Lei $\mathrm{N}^{\mathrm{0}} 12.711$, de 29 de Agosto de 2012, que dispõe sobre o ingresso nas universidades federais e nas instituições federais de ensino técnico de nível médio e dá outras providências. No seu artigo 1o coloca: "No preenchimento das vagas de que trata o caput deste artigo, 50\% (cinquenta por cento) deverão ser reservados aos estudantes oriundos de famílias com renda igual ou inferior a 1,5 salário-mínimo (um saláriomínimo e meio) per capita" (BRASIL, 2012).

O Decreto $\mathrm{n}^{\mathrm{o}} 7.234$, de 19 de julho de 2010, que dispõe sobre o Programa Nacional de Assistência Estudantil / PNAES, no seu artigo 5o , considera como fator de concessão o indicador de renda onde "Serão atendidos no âmbito do PNAES prioritariamente estudantes oriundos da rede pública de educação básica ou com renda familiar per capita de até um salário mínimo e meio, sem prejuízo de demais requisitos fixados pelas instituições federais de ensino superior" (BRASIL, 2010). 


\section{A DEFINIÇÃO DO PERFIL DE VULNERABILIDADE PARA ACESSO À POLÍTICA DE PERMANÊNCIA NO ENSINO SUPERIOR \\ DOI: http://dx.doi.org/10.5007/1983-4535.2015v8n1p132}

A proposição de bolsa do Ministério da Educação, para atendimento às questões de vulnerabilidade social e da permanência, coloca no Manual de Gestão da Bolsa Permanência, os seguintes critérios: possuir renda familiar per capita não superior a um salário-mínimo e meio; estar matriculado em cursos de graduação com carga horária média mínima de cinco horas diárias.

Tanto a concepção do PNAES, como a atual proposta de Bolsa permanência do MEC, apontam para a definição de vulnerabilidade trazendo a renda per capita como fator prioritário de concessão.

O desafio está em construir o conhecimento necessário para definição de um perfil socioeconômico que supere a visão mercantilista e amplie a visão sobre a vulnerabilidade social que estabelece os critérios para o atendimento aos estudantes nas políticas de permanência.

\subsection{DELIMITAÇÃO DA VULNERABILIDADE PARA GESTÃO DA POLÍTICA DE PERMANÊNCIA NO ENSINO SUPERIOR}

Para o Assistente social que executa as Políticas de Assistência, o desafio passa pelo posicionamento na elaboração de procedimentos, como a metodologia para definição do perfil de vulnerabilidade, que supere a visão instrumental centrada somente no mercado, e pensar sobre os instrumentos implica em posicionamento crítico ao considerar a realidade e suas mediações, ponderando os compromissos éticos e políticos.

Para Santos (2013), quando se refere às dimensões do exercício profissional do assistente social, coloca a importância do referencial técnico operativo, e para isso afirma

ser necessário um conhecimento sobre as particularidades dos instrumentos e técnicas que dão operacionalidade à profissão e para isso é importante tratar das questões como: os instrumentos utilizados historicamente pela profissão; a relação entre os instrumentos e conhecimento da realidade; as possibilidades de criação e inovação de instrumentos de intervenção; o desvendamento dos equívocos no entendimento de teoria, instrumentos e técnicas; a relação de unidade entre as dimensões da intervenção profissional; a utilização de instrumentos; o real papel dos instrumentos e técnicas na intervenção (SANTOS, 2013, p.9).

Considerando a intervenção e os instrumentos e técnicas necessários para sua efetivação, a compreensão da realidade necessariamente deve considerar o referencial teórico metodológico, e, para Santos (2013, p.98), 
Pensar a intervenção é fundamental numa profissão cuja natureza é prioritariamente interventiva. A intervenção é constituída e constituinte de várias dimensões: ético-política, teórico metodológica e técnico operativa. Pensá-las como unidade sendo que a dimensão técnico operativa deriva das demais vem sendo a grande preocupação no debate atual sobre instrumentos e técnicas no Serviço Social.(...) percebe-se uma grande preocupação com a adoção de uma realidade estritamente instrumental, sobretudo por essa concepção estar em ressonância com a concepção de educação superior defendida pelo MEC. Desse modo sob a alegação de se estar trabalhando com uma visão de unidade, focalizam-se, muitas vezes, os fundamentos de intervenção sem se chegar às particularidades dos elementos constituintes da dimensão técnico operativa do Serviço Social.

Para Chauí (1995, p.339), ao se pensar sobre a utilização de uma metodologia, tem que se verificar a intencionalidade, pois "nem todos os meios são justificáveis, mas apenas aqueles que estão de acordo com os fins da própria ação (...) fins éticos exigem meios éticos”.

A determinação de um perfil socioeconômico exige a superação dessa realidade instrumental, para compreensão dos aspectos substantivos e de acordo com a legislação, que determina as competências do profissional de Serviço Social. Cabe "realizar estudos socioeconômicos com usuários, para fins de benefícios e serviços sociais junto a órgãos da administração pública direta e indireta, empresas privadas e outras entidades" (BRASIL, 1993).

\section{METODOLOGIA}

No desenvolvimento dessa pesquisa, utilizou-se uma abordagem qualitativa de natureza aplicada com caráter descritivo do estudo multi-caso. Conforme Roesch (1999, p.154), “[...] pesquisa qualitativa é apropriada para a avaliação formativa, quando se trata de melhorar a efetividade de um programa, ou plano, ou mesmo quando é o caso da proposição de planos [...]”. Ainda segundo a autora, a ênfase é na perspectiva do sujeito pesquisado e capta as interpretações das pessoas.

Para coleta de dados foi utilizada a pesquisa documental, bibliográfica e o questionário, encaminhado via e-mail em novembro de 2013 aos gestores das equipes de Assistentes Sociais de cinco universidades. Nas informações obtidas buscou-se identificar as formas utilizadas para o estudo socioeconômico nas mesmas.

Entre os objetivos procura-se identificar os componentes da metodologia de análise, ou seja, o que só pode ser analisado e que é de domínio dos profissionais de Serviço Social, e identificar de que maneira são utilizados os critérios, e como é preservada a igualdade de 
direitos e a isonomia entre os estudantes. Considera-se necessário alavancar a metodologia de análise utilizada atualmente pelos profissionais que realizam os estudos, citando sua metodologia, indicadores e agravantes considerados na análise.

As universidades pesquisadas foram: Universidade Federal de São Paulo/UNIFESP, Universidade Federal do Espírito Santo/UFES, Universidade Federal do Rio de Janeiro/UFRJ, Universidade Federal do Paraná/UFPR, Universidade Federal do Rio Grande do Sul/UFRGS e Universidade Federal de Santa Catarina/UFSC.

Essas universidades federais das regiões sul e sudeste foram definidas como unidades de pesquisa, por apresentarem realidades socioeconômicas mais aproximadas. Essa definição ocorreu com base nas informações divulgadas pelo Instituto Brasileiro de Geografia e Estatística/IBGE, no documento síntese de indicadores sociais, que apresenta uma análise das condições de vida da população brasileira em 2012 (IBGE,2013). Este estudo informa as dimensões de análise e algumas das principais características observadas nos diferentes estratos geográficos e populacionais. Os indicadores selecionados levam em conta os eixos de condições de vida, desigualdade e exclusão social, assim como as dimensões de espaço e tempo. Esse estudo divulga os aspectos sobre saúde, demográficos, Famílias e domicílios, Educação, Trabalho, Padrão de vida, Distribuição de renda e Saúde no Brasil, Grandes Regiões e Unidades da Federação, e também para Regiões Metropolitanas. São elaborados, principalmente, a partir da Pesquisa Nacional por Amostra de Domicílios - PNAD realizada em 2012.

No sentido de identificar fatores utilizados para delimitação do perfil de vulnerabilidade socioeconômica, foram elaboradas as seguintes questões, enviadas aos gestores:

a) Qual a metodologia utilizada para realização da análise socioeconômica?

b) Como foi construída a metodologia utilizada?

c) Como são definidos os indicadores e critérios?

d) Como ocorre o compartilhamento dos conhecimentos e das orientações entre os profissionais para realização da análise?

e) Existe uma instrução ou manual metodológico para orientação e uso do Assistente Social?

\section{RESULTADOS DAS UNIVERSIDADES PESQUISADAS}

As informações a seguir foram respondidas pelos gestores das áreas de Assistência Estudantil e Permanência das universidades, por e-mail, bem como foram enviados os editais 
e resoluções, considerados pelos mesmos como respostas a algumas questões da pesquisa. A Universidade Federal do Paraná/UFPR não retornou a pesquisa e a Universidade Federal do Rio Grande do Sul/UFRGS respondeu às questões enviadas sugerindo consulta à página da internet.

\subsection{DELIMITAÇÃO DA VULNERABILIDADE NA UNIFESP}

A Política de Assistência Estudantil da UNIFESP "visa criar condições de acesso e aproveitamento pleno da formação acadêmica aos estudantes". É destinada a todos os estudantes matriculados nos diversos cursos de graduação de todos os campi da Universidade Federal de São Paulo, que se apresentam em situação de vulnerabilidade social e econômica.

O Perfil prioritariamente atendido está em conformidade com o Artigo $5^{\circ}$ do Decreto $\mathrm{n}^{\mathrm{o}}$ 7.234, de 19 de julho de 2010, que dispõe sobre o Plano Nacional de Assistência Estudantil (PNAES). No âmbito do PNAES, são atendidos prioritariamente estudantes oriundos da rede pública de educação básica ou com renda familiar per capita de até um salário mínimo e meio, sem prejuízo de demais requisitos fixados por critérios socioeconômicos adotados na universidade. A análise é realizada por uma Comissão de Avaliação e Estudo formada pelas Assistentes Sociais dos Núcleos de Apoio ao Estudante - NAEs, pela Assistente Social da Pró-Reitoria de Assuntos Estudantis e pela Coordenadoria de Ações Afirmativas e de Permanência - CAAP.

Esta universidade coloca a preocupação com a qualificação e a validade dos critérios para a atribuição dos auxílios, devido às constantes mudanças na sociedade contemporânea, refletidas nas diversas manifestações da questão social vivenciadas cotidianamente. Assim, a Comissão de Avaliação e Estudo vem aperfeiçoando desde 2010 as formas de inscrição, os prazos para pedidos, os instrumentos de entrevista e coleta de dados da situação socioeconômica, e a metodologia para análise e concessão de bolsas socioeconômicas aos estudantes.

Para atender a esta orientação, é utilizada a análise combinada de variáveis; nenhuma variável isolada é suficiente para compor o perfil socioeconômico, mas sim a combinação destas variáveis. A atribuição de auxílios é assim feita a partir dos graus de vulnerabilidade identificados na população global de estudantes que atendem aos requisitos. A definição do valor a ser concedido é com base na situação de vulnerabilidade apresentada pelo estudante e avaliada, de forma sempre global, pelo Assistente Social. 


\section{A DEFINIÇÃO DO PERFIL DE VULNERABILIDADE PARA ACESSO À POLÍTICA DE PERMANÊNCIA \\ NO ENSINO SUPERIOR \\ DOI: http://dx.doi.org/10.5007/1983-4535.2015v8n1p132}

São estabelecidos níveis de vulnerabilidade socioeconômica, para garantir o princípio da equidade de condições. Deste modo, a atribuição dos auxílios é realizada não apenas a partir da finalidade representada por modalidade de auxílios, e sim pelas necessidades dos estudantes, pela identificação de perfis socioeconômicos e sua correspondente faixa de valores, onde é caracterizada situação de extrema vulnerabilidade socioeconômica (Perfil I), alta vulnerabilidade socioeconômica (Perfil II), média vulnerabilidade socioeconômica (Perfil III), baixa vulnerabilidade socioeconômica (Perfil IV) e vulnerabilidade financeira (Perfil V).

Nesse caso a vulnerabilidade socioeconômica é considerada a partir do conjunto de situações que podem comprometer a permanência do estudante da UNIFESP, sendo considerados como indicadores de vulnerabilidade socioeconômica: o número de membros do Grupo Familiar (GF); moradia do estudante ou da família (MR); procedência escolar (PE); a renda per capita do grupo familiar (RT); o Impacto de doenças graves na organização familiar (DG); a situação de trabalho do grupo familiar e do próprio estudante (ET).

São observadas também variáveis Atenuantes da situação socioeconômica (AT): buscam apontar, qualificar e quantificar uma situação de estabilidade financeira e/ou capacidade de acesso a bens de consumo e serviços da família e do estudante. São consideradas (ATs) prioritariamente: curso de graduação concluído anteriormente; acesso a bens e serviços privados; patrimônio familiar apresentado; estabilidade de emprego e renda; aplicações financeiras.

As variáveis Agravantes (AGs) da situação socioeconômica são: participação em programas de transferência de renda governamentais; residência familiar localizada em área irregular ou de risco; despesas com moradia do grupo familiar e moradia provisória do estudante; desemprego do provedor financeiro da família; estudante provedor financeiro do grupo familiar; fragilização de vínculos afetivos relacionais e de pertencimento social (etário, étnico, de gênero, por deficiência, orientação/ identidade sexual).

A partir da consideração das variáveis qualificadoras apresentadas, foi elaborado o Índice de Classificação (IC). Os candidatos ao programa serão priorizados em ordem crescente dos valores do seguinte Índice de Classificação, calculado pela fórmula: RT/GF x MR x EP x DG x ET x AT x AG.

Conforme a metodologia, a classificação socioeconômica para a concessão dos auxílios é realizada por meio do cálculo do Índice de Classificação combinado à análise social do Assistente Social para cada estudante. 


\section{A DEFINIÇÃO DO PERFIL DE VULNERABILIDADE PARA ACESSO À POLÍTICA DE PERMANÊNCIA NO ENSINO SUPERIOR \\ DOI: http://dx.doi.org/10.5007/1983-4535.2015v8n1p132}

A documentação é apresentada na entrevista individual e analisada pela equipe de Assistentes Sociais. À Comissão de Avaliação cabe analisar os documentos e solicitar outros que eventualmente sejam necessários para complementação da análise.

A construção da metodologia, ocorreu no estudo de uma proposta inicial para os critérios de seleção, e a partir desta diretriz geral, foram realizados outros estudos e análises e estabelecidos os critérios socioeconômicos. A proposição foi então apresentada pela Coordenadoria de Ações Afirmativas e Políticas de Permanência ao Conselho de Assuntos Estudantis (CAE), que aprovou o conjunto de critérios socioeconômicos a partir dos quais é feita a seleção dos alunos a serem beneficiados.

Nessa metodologia utiliza-se a valorização numérica de indicadores que permitem a definição de um índice de classificação do menor para o maior.

\subsection{DELIMITAÇÃO DA VULNERABILIDADE NA UFRJ}

Nos processos de seleção das bolsas de assistência estudantil da UFRJ, é utilizada a análise de documentação socioeconômica familiar apresentada pelos alunos, e não há entrevistas. A metodologia foi construída com a equipe da Superintendência Geral de Políticas Estudantis/SuperEst /DAE, e para os indicadores foram consideradas as discussões do Grupo de Trabalho do FONAPRACE e as sugestões da equipe de Assistentes Sociais da Divisão de Apoio ao Estudante. Os critérios para a seleção e renovação das bolsas são dispostos em Resolução do Conselho de Ensino e Graduação. São realizadas reuniões semanais em épocas de seleção, para tudo que precisa ser discutido. São consideradas prioritariamente as diretrizes do Programa Nacional de Assistência Estudantil (PNAES).

Os assistentes sociais da DAE realizam o estudo socioeconômico com base em indicadores previamente estabelecidos, e a análise socioeconômica de forma geral, prevê além de dados objetivos de renda, outros indicadores sociais, que interferem diretamente nas perspectivas do indivíduo, e/ou de sua família, em ter acesso a bens e serviços que garantam seus direitos de cidadania.

Nos processos de seleção, os assistentes sociais da DAE analisam a documentação apresentada pelo aluno, conforme estabelecido nos editais específicos. Outros instrumentos podem ser utilizados como a visita domiciliar e/ou entrevista, objetivando esclarecer questões não elucidadas pela documentação apresentada. 


\section{A DEFINIÇÃO DO PERFIL DE VULNERABILIDADE PARA ACESSO À POLÍTICA DE PERMANÊNCIA \\ NO ENSINO SUPERIOR \\ DOI: http://dx.doi.org/10.5007/1983-4535.2015v8n1p132}

Para a avaliação das condições socioeconômicas dos alunos, são considerados os seguintes indicadores: a Renda Per Capita; os Bens: pouco significativos (necessários para a manutenção básica da família) ou muito significativos (que demonstrem padrão de vida diferenciado); Despesas mensais da família como pagamento de aluguel ou financiamento; Local de Moradia: considera-se a localização da moradia do aluno e de sua família a partir da delimitação de zonas geográficas; Condições de Moradia: moradia provisória, vaga alugada ou pensão, quando seu local de origem inviabiliza sua ida diária para a Universidade ou moradia permanente; Escolaridade dos pais: Dado que aponta para as perspectivas de inserção no mercado de trabalho; Principal provedor: Tipo de inserção no mercado de trabalho do membro provedor da família, se formal, informal ou trabalhador autônomo, de forma a avaliar se há vínculo precário, renda variável ou garantias trabalhistas. É observado o aluno que reside sozinho, antes mesmo de seu ingresso na universidade, e que arca com todos os custos para a sua subsistência, sem qualquer suporte familiar; Os problemas de saúde: referem-se a problemas de saúde do aluno ou de um dos membros de sua composição familiar. Considerase a doença grave ou crônica que impeça a inserção no mercado de trabalho e ocasione despesas que onerem significativamente o orçamento familiar.

Para cada um desses indicadores é estabelecida uma pontuação que, somada à renda bruta per capita, resulta na pontuação final. Os alunos são classificados em ordem crescente a partir da pontuação final.

Nota-se nessa metodologia a opção pela estratificação social, que diz respeito à classificação dos indivíduos e grupos sociais segundo determinadas qualidades ou atributos, separando-os nas classes sociais correspondentes. Os principais atributos utilizados para essa separação são: educação, renda, status social, profissão, ocupação e origem social. A pontuação relativa a cada indicador considerado pode ser examinada neste instrumental e diz respeito à valoração do menos complexo ao mais complexo.

O instrumental proposto voltou-se para um sistema de pontuação simples que deve resultar, por correlações, em um tipo de classificação por estratos. Nesse sentido, a avaliação foi feita de forma convencional abrangendo estratos definidos pelo número de pontos acumulados. A estratificação tem como núcleo central as condições de vida da família, informações e considerações sobre suas rendas, natureza da atividade ocupacional dos familiares, composição demográfica familiar, nível educacional e condições habitacionais. 


\subsection{DELIMITAÇÃO DA VULNERABILIDADE NA UFES}

A metodologia utilizada é a análise documental, e os documentos analisados são os mesmos utilizados na comprovação de renda da legislação da Reserva de Vagas (Lei 12.711, de 29 de agosto de 2012 e a Portaria $n^{\circ} 18$, de 11 de outubro de 2012). Em alguns casos são realizadas entrevistas.

A metodologia utilizada foi uma decisão da atual gestão da política de assistência estudantil, no sentido de utilizar a análise da renda de até um salário mínimo e meio per capita. A portaria considerada estabelece para definição de classificação a média mensal dos rendimentos brutos dividido pelo número de pessoas da família do estudante. Não são utilizados indicadores atualmente.

Mensalmente são realizadas reuniões da Comissão Permanente de Verificação - CPV, composta pelos profissionais Assistentes Sociais envolvidos na análise, sendo então planejados os processos de cadastramento dos estudantes, discussão dos casos omissos, avaliação dos processos/procedimentos e proposição de mudanças a serem encaminhadas à gestão. São também elaborados Editais que trazem os critérios e procedimentos para cadastramento dos estudantes no Programa de Assistência Estudantil - PROAES.

\subsection{DELIMITAÇÃO DA VULNERABILIDADE NA UFSC}

O estudo na UFSC é realizado por equipe de Assistentes Sociais, cuja metodologia foi construída e passou por revisões, que aconteceram em reuniões periódicas. A seleção é realizada por meio da análise do cadastro socioeconômico, da entrevista e da documentação comprobatória apresentada, onde são definidos os indicadores sociais utilizados para definição do Índice Socioeconômico de cada aluno.

São elaborados Editais que trazem os critérios e procedimentos para preenchimento do cadastro socioeconômico. A análise socioeconômica tem como referencial os seguintes indicadores agravantes da situação familiar, considerando-se: Renda familiar; número de dependentes; despesas do (a) aluno (a) com moradia e distância da moradia, considerando-se a localização da moradia do aluno e de sua família; situações de doença na familiar, referemse a problemas de saúde do aluno ou de um dos membros de sua composição familiar, que impeçam a inserção no mercado de trabalho e ocasionem despesa familiar; desemprego e situações de desagregação familiar como óbito, separação ou divórcio recentes. 


\section{A DEFINIÇÃO DO PERFIL DE VULNERABILIDADE PARA ACESSO À POLÍTICA DE PERMANÊNCIA \\ NO ENSINO SUPERIOR \\ DOI: http://dx.doi.org/10.5007/1983-4535.2015v8n1p132}

Dessa forma, o índice socioeconômico é definido por meio da seguinte fórmula: $\mathrm{C} \mathrm{x}$ R/VR x N. Onde (C) é a constante $(0,6$ ou 0,4 ou 0,8$)$ referente aos agravantes da situação familiar como doença, despesas com moradia e outros $(40 \% / 60 \% / 80 \%)$, relacionados aos percentuais do impacto sobre a renda familiar, (R) renda bruta familiar, (VR) salário mínimo e $(\mathrm{N})$ o número de dependentes da renda familiar.

Nessa metodologia observa-se também, a valorização numérica de indicadores que permitem a definição de um índice de classificação do menor para o maior. A equipe iniciou a elaboração de um caderno metodológico para orientação ao assistente social e realiza reuniões para análise das situações divergentes, para esclarecer dúvidas de interpretação dos dados e para a definição de indicadores.

\subsection{DELIMITAÇÃO DA VULNERABILIDADE NA UFRGS}

$\mathrm{Na}$ consulta realizada à página da Pró Reitoria de Assuntos Estudantis/PRAE da UFRGS(2013), verifica-se que o Edital de seleção da casa do estudante universitário $\mathrm{N}^{\circ} 02 / 2013$ apresenta os critérios de seleção como: entrevista, documentação completa e estudo socioeconômico. A avaliação socioeconômica prioriza estudantes com renda familiar per capita de até um salário mínimo e meio, conforme orientação do Decreto 7.234/2010, do Decreto $\mathrm{n}^{\mathrm{o}} 7.824$ de 11/10/12 e da Portaria Normativa $\mathrm{n}^{\circ} 18$ de 11/10/12.

São considerados no estudo socioeconômico os critérios de classificação: Renda Familiar; situação de moradia do estudante e grupo familiar; situação de saúde do estudante e grupo familiar; situação de escolaridade do estudante e grupo familiar; despesas familiares. Tem como critérios de desempate: viabilidade de freqüentar a universidade, e menor tempo de curso integralizado, sempre respeitando a Renda per capita.

\subsection{ANÁLISE DAS INFORMAÇÕES PESQUISADAS}

Na política de assistência estudantil das universidades pesquisadas, enquanto política seletiva, faz-se necessária a realização de seleção dos acadêmicos que virão a ser beneficiados com os programas, projetos e serviços de assistência estudantil.

A política seletiva em todas as universidades pesquisadas tem como principal agente executor o profissional de Serviço Social, que realiza análises socioeconômicas. Estas são realizadas a partir de análise dos dados nos formulários, e de documentações solicitadas aos acadêmicos, que comprovem a sua situação. Percebe-se que a metodologia do estudo 
socioeconômico foi elaborada pelos Assistentes Sociais, em reuniões de equipe, e/ou em comissões formadas para compartilhamento dos dados e informações.

Não foram informadas referências bibliográficas específicas de metodologias, mas verifica-se que os conhecimentos construídos consideram prioritariamente as questões de legislação. Apenas uma universidade não realiza a entrevista como instrumento para o estudo. Os documentos onde são explicitados os critérios, procedimentos e indicadores são editais e Resoluções. Não foi informada a existência de manuais ou normativas metodológicas de orientação, para interpretação dos dados e informações, ou para definição dos indicadores. Somente uma universidade indicou iniciar esse procedimento.

O estudo socioeconômico é parte intrínseca das ações desenvolvidas por assistentes sociais e pressupõe conhecimentos específicos adquiridos ao longo do processo de formação, como a compreensão das condições sociais em que vivem os estudantes, e a escuta qualificada de suas demandas. A elaboração da sistemática metodológica do estudo socioeconômico, e a identificação e sistematização dos indicadores e agravantes sociais, que constituem a determinação do perfil de vulnerabilidade social, têm sido analisadas a partir do público-alvo atendido, e principalmente com base nos documentos relacionados à sua composição.

Embora as formas adotadas de construção das metodologias apresentem a preocupação com as bases teóricas, estas são principalmente desenvolvidas a partir dos conhecimentos dos Assistentes Sociais, e não fíca clara a definição de uma teoria específica para estudo socioeconômico.

\section{CONSIDERAÇÕES FINAIS}

Compreende-se que o conhecimento teórico metodológico, ético e político do Assistente Social, que implica na sistemática metodológica do estudo socioeconômico, deve ser construído a partir de instrumentais técnico-operativos, acompanhado de questionário, entrevistas e acolhimento aos usuários, seguido de parecer social. A sutileza do estudo dos instrumentos e técnicas, para definição do perfil de vulnerabilidade, deve considerar a postura crítica e de construção de um conhecimento que inclua a totalidade dos indicadores sociais, tendo por parâmetro um referencial teórico, metodológico, ético e político.

Entende-se que isto é essencial no uso de metodologia para definição de vulnerabilidade social, que supere a visão instrumental, e que verifique as premissas da garantia da ampliação do acesso, e a integralidade das questões de exclusão social. 


\section{A DEFINIÇÃO DO PERFIL DE VULNERABILIDADE PARA ACESSO À POLÍTICA DE PERMANÊNCIA \\ NO ENSINO SUPERIOR \\ DOI: http://dx.doi.org/10.5007/1983-4535.2015v8n1p132}

A importância do conhecimento sob essa perspectiva se revela por oferecer a possibilidade de compreensão dos aspectos sociais e históricos, que interferem nas relações, bem como nas condições de vida dos estudantes. A partir da compreensão da realidade, do conhecimento da instituição (universidade) com a qual se trabalha, o profissional tem condições de escolher e criar os instrumentos e as técnicas mais adequadas à situação estudada, e buscar a forma de operacionalizá-lo, de maneira que ajude a se aproximar das finalidades de sua ação.

Nas universidades pesquisadas nota-se que não há uma definição única dos conhecimentos utilizados, fato este que pode estar relacionado à questão da autonomia. No entanto, percebe-se na escolha dos critérios adotados, que eles superam a visão estabelecida unicamente pela renda, ampliando a concepção mercantilista de vulnerabilidade, sendo que somente uma universidade optou por seguir exclusivamente essa definição. Constata-se que a construção de um conhecimento metodológico ocorre a partir das percepções dos Assistente Sociais sobre aspectos impactantes na realidade social do estudante.

Apesar dos critérios adotados estarem em sua maioria definidos em editais, sugere-se a elaboração de manuais metodológicos para orientação aos profissionais, de maneira que os conhecimentos utilizados possam ser explicitados para construção de um conjunto de conhecimentos que reflitam a realidade socioeconômica.

Embora a análise utilize documentação, que é verificada em algumas situações por meio da entrevista, na definição dos indicadores e dos critérios, o conhecimento profissional é essencialmente definidor. Seria interessante oportunizar encontros e reuniões entre as equipes das universidades que realizam os estudos, para um maior compartilhamento dos conhecimentos, a fim de garantir a identidade no estudo socioeconômico.

A Política de Gestão da Permanência, e especificamente a realização dos estudos socioeconômicos, podem contribuir essencialmente para melhorar o acesso às universidades. Existem formas e estratégias de distribuir e compartilhar o conhecimento utilizado pelo profissional, para definição dos indicadores e critérios empregados no uso da metodologia, possibilitar superação das divergências, resultante da subjetividade na interpretação dos dados utilizados nas análises realizadas, uma vez que as características e alternativas das variáveis são definidas por conhecimentos construídos, em uma forma de organização e vivência muito específica do recorte social. 
Indica-se a formação de grupos ou núcleos de estudo com o objetivo de realizar atividades de pesquisas, avaliação e compartilhamento na interface com as demais Universidades, possibilitando dentre as atividades desenvolvidas pelos assistentes sociais, que atuam neste contexto, a reestruturação e o monitoramento da metodologia de análise socioeconômica e do estudo do perfil dos estudantes atendidos nos programas de assistência estudantil, de modo a estabelecer um processo de melhoria contínua nessa atividade tão importante.

\section{REFERÊNCIAS}

ABRAMOVAY, Miriam, et al. Juventude, violência e Vulnerabilidade Social na América Latina; desafios para políticas públicas. Brasília. UNESCO. BID. 2002.

BRASIL. Presidência da República. LEI N ${ }^{0}$ 8.662, de 7 de junho de 1993. Dispõe sobre a profissão de Assistente Social e dá outras providências. Publicado no DOU07.06. 1993. Disponível em: $<$ http://www.planalto.gov.br/ccivil_03/leis/L8662.htm. >. Acesso em: 06.08.2013

. Decreto $n^{0}$ 6.096, de 24 de abril de 2007. Institui o Programa de Apoio os Planos de Reestruturação e Expansão das Universidades Federais - REUNI. Publicado no DOU de 25.4.2007. Disponível em: <http://www.planalto.gov.br/ccivil_03/_ato2007-

2010/2007/decreto/d6096.htm>. Acesso em: 06.08.2013

. Presidência da República. Decreto n ${ }^{\circ} 7234$, de 19 de julho de 2010. Dispõe sobre o Programa Nacional de Assistência Estudantil - PNAES. Publicado no DOU de 20.7.2010 Disponível em: < http://www.planalto.gov.br/ccivil_03/_ato20072010/2010/decreto/d7234.htm>. Acesso em: 06.08.2013

. Presidência da República. Lei No 12.711, de 29 de agosto de 2012. Dispõe sobre o ingresso nas universidades federais e nas instituições federais de ensino técnico de nível médio e dá outras providências. Publicado no DOU 29.08.2012. Disponível em: $<$ http://www.planalto.gov.brato2011-2014/2012/lei/112711.htm>. Acesso em: 06.08.2013

CASTEL, Robert. A dinâmica dos processos de marginalização: da vulnerabilidade à “desfiliação". Cadernos CRH, no 26 e 27, pp. 19-40, 1997a.

. As armadilhas da exclusão. In: Desigualdade e a questão social. São Paulo: EDUC, pp. 15-48. 1997b,

CASTRO, Alba Tereza Barros de. Política Educacional e direitos sociais: reconfiguração do ensino superior no Brasil. In: BOSCHETTI, Ivanete. Capitalismo em crise, política social e direitos. São Paulo: Cortez, 2010

CFESS. Conselho Federal de Serviço Social. Resolução no 493/2006 de 21 de agosto de 2006. Dispõe sobre as condições éticas e técnicas do exercício profissional do assistente social. 
Disponível em: <http://www.cfess.org.br/arquivos/Resolucao_493-06.pdf > . Acesso em: 07.08.2013

CHAUÍ, Marilena de Souza. A universidade pública sob nova perspectiva. 1995. Disponível em: $<$ http//www.scielo.br/pdf/rbedu/n24/n2 a02.pdf. $>$ Acesso em: 12.04.2013

CRUZ JÚNIOR, João Benjamim. Organização e Administração de entidades públicas: Aspectos Econômicos, Políticos e Sociais de um Paradigma Emergente. Revista de Administração Pública. Rio de Janeiro, Fundação Getúlio Vargas, 22(3): 3-21, jul./set. 1988.

DIETERLEN, Paulette. Derechos necesidades básicas y obligación institucional In: ZICCARDI, Alicia (org). Pobreza Desigualdad Social y Ciudadanía: los Limites de Las Políticas Sociales en America Latina. Buenos Aires. CLACSO, 2001. p. 13-22

IBGE.Instituto Brasileiro de Geografia e Estatística. Síntese de indicadores sociais. Uma análise das condições de vida da população brasileira 2013. Rio de janeiro 2013. Disponível em: http://biblioteca.ibge.gov.br/d_detalhes.php?id=266778. Acesso em: 06.11.2013.

KAZTMAN, R. Segregacion espacial, empleo y pobreza en Montevideo. In: Revista de la CEPAL. 85. Santiago de Chile: CEPAL. 2005.

MENNA, F. R. C.; SAUER, L. Inovações gerenciais e qualidade de vida no trabalho: a realidade da EPAGRI, 1998. Disponível em: <www.abepro.org.br/biblioteca/ENEGEP 1998_ART 058. pdf>. Acesso em: 06.08.2013.

MIRANDA, L. Gestão de Processos na Modernização da Administração Pública Central, Regional e Local. Insight SINFIC, n. 35, outubro 2005. Disponível em: <www. sinfic. $\mathrm{pt} /$.../sinfic/.../Dossier 2.GestãoProcessos.html>. Acesso em: 04.08.2013

MOTTA, Paulo Roberto. Diagnóstico e Inovação Organizacional. In: Planejamento organizacional: dimensões sistêmico-gerenciais. Porto Alegre: Fundação para o Desenvolvimento de RH, 1979.

ROCHA, Sheila Nadíria R. As perspectivas de operacionalização da Assistência Estudantil nos anos 90: Análise da experiência, Recife, 1997.

ROESCH, Sylvia Maria Azevedo. Projetos de estágio e de pesquisa em administração. 2. ed. São Paulo: Atlas, 1999.

SANTOS, Claudia Mônica. Na prática a teoria é outra? : mitos e dilemasna relação entre teoria, prática, instrumentos e técnicas no serviço social. 3ed.Rio de Janeiro: Lumen Juris, 2013.

UFRGS. Pró Reitoria de Assuntos Estudantis / PRAE Edital de seleção da casa do estudante universitário. Disponível em: <http://www.ufrgs.br/prae/editais/editais-2013-2/editalmoradia-estudantil-2013-2>. Acesso em: 05 jun 2014. 